\title{
ACERCAMIENTO MÚLTIPLE A LOS CUENTOS DE GUSTAVO DÍAZ SOLÍS
}

POR

\author{
Cósimo MandRILlo
}

\section{Díaz Solís}

Gustavo Díaz Solís nació en 1920 y Marejada, ${ }^{1}$ su primer libro, se publicó veinte años después. Al aparecer, en 1963, Cinco cuentos el autor había publicado la casi totalidad de su obra. Habría que esperar hasta 1968 para que con la aparición de Ophidia y otras personas tuviésemos al alcance la totalidad de los escasos veintiún cuentos que el escritor ha publicado a lo largo de su vida.

No estamos pues frente a un escritor prolífico; o en caso contrario - para quienes prefieran suponer que Díaz Solís ha escrito otros textos que no ha dado a la luz- hemos topado con un autor proverbialmente pudoroso y autocrítico.

Como fuese, Díaz Solís logra méritos por partida doble merced a la brevedad de su obra. Antes que nada, porque a pesar de tal cortedad es de manera incuestionable uno de los cuentistas más importantes de la literatura venezolana. La segunda, porque en un país donde tradicionalmente no ha habido, por parte de sus escritores, contención alguna a la hora de publicar, el haber optado por la brevedad primero, y el silencio después, reafirma a Díaz Solís como una excepción en el panorama literario nacional.

Óscar Sambrano Urdaneta ha caracterizado con precisión el relato venezolano hasta la aparición de los primeros cuentos de Díaz Solís; panorama en el cual resaltaban, según él, los siguientes rasgos: " $1^{\circ}$ Realismo literario; $2^{\circ}$ Tendencia a sobrecargar la frase de elementos decorativos; $3^{\circ}$ Preferencia marcada por la descripción del paisaje rural; $4^{\circ}$ Personajes que en la mayoría de los casos están tomados de los medios campesinos y, en menor escala, de las ciudades, incluyendo sus faenas, trajes, costumbres, tradiciones, creencias, etc. $^{2}$

\footnotetext{
${ }^{1}$ Gustavo Díaz Solís, Marejada (Caracas: Editorial Bolívar, 1940); Llueve sobre el mar (Caracas: Asociación de Escritores Venezolanos, 1943); Cuentos de dos tiempos (México: Gráfica Panamericana, 1950); Cinco cuentos (Caracas: Asociación de Escritores Venezolanos, 1963); Ophidia y Otras Personas (1969; Caracas: Monte Ávila Editores, 1989), Arco secretoy otros cuentos (Caracas: Monte Ávila Editores, 1973); Exploraciones Críticas (Caracas: Universidad Central de Venezuela, 1968).

${ }^{2}$ Oscar Sambrano Urdaneta, Prólogo a Cinco cuentos, 8.
} 
Pocos textos de Díaz Solís sucumben a la tentación de incorporar estas "marcas". Acucioso lector de la literatura inglesa y norteamericana - de la cual ha hecho traducciones y estudios- es muy probable que Díaz Solís extrajera de esa fuente su lenguaje tan particular en el contexto nacional.

$\mathrm{El}$ escritor evade igualmente los temas comunes en la narrativa de su momento y llena su obra con personajes y temas fantásticos. En ella abundan serpientes y otras bestias, objetos y niños cargados de una inagotable carga simbólica que enriquecen al texto mucho más allá de la siempre aparente simpleza de su estructura y de su anécdota. Y si en algún momento revierte esta tendencia temática, se dedica entonces al cultivo de un psicologismo capaz de poner en juego poderosas y variadas fuerzas interiores en sus personajes. Logra por esta vía textos en los que la brevedad potencia su capacidad de sugerir. Todo esto, paradójicamente, sin que se le pueda incluir entre los cultores del realismo mágico, tan experimentado como discutido en el continente.

Escritor solitario si no de obra aislada, Díaz Solís no participa en grupos como no sea por su inicial relación con el Grupo "Vide" surgido en la Universidad Central de Venezuela en momentos en que aparece Marejada. A juzgar por la escasa trascendencia de ese grupo puede coligirse que habrá sido igualmente pobre su influencia en la carrera literaria de Díaz Solís. Suele asociársele también con Contrapunto. No figura sin embargo entre quienes firman el manifiesto con el cual este grupo se dio a conocer. Existe sí una subterránea conexión entre el propósito de Contrapunto de "universalizar la literatura venezolana y la obra de Díaz Solís. Díaz Solís está, sin embargo, tan cerca de algunos integrantes de Contrapunto como lejos de otros. Proximidad perfectamente constatable en los casos de Andrés Mariño Palacios y Humberto Rivas Mijares con quienes comparte la tendencia a la creación de cuentos de atmósfera y el interés por la exploración psicológica de los personajes; o con Óscar Guaramato a quien lo acerca la inclinación hacia un lenguaje de gran laconismo aunque sin perder un cierto tono poético que se afirma sobre la perfecta selección de las imágenes y no sobre su abundamiento.

No ha errado, en fin, Óscar Sambrano Urdaneta cuando opta por incluir a Días Solís en la Generación del 42 - Luis Pastori, Benito Raul Lossada, Pedro Francisco Lizardo, Aquiles Nazoa, Ida Gramko, Ana Enriqueta Terán, Oscar Guaramato, Humberto Rivas Mijares, Antonio Márquez Salas - en la que figuran, como puede verse, algunos de los nombres más conspicuos de Contrapunto.

Este artículo pretende ofrecer una breve perspectiva de la obra de Díaz Solís en sus rasgos formales más pertinentes y a continuación analizar en sus cuentos el valor simbólico de la serpiente, elemento que se encuentra con inusual frecuencia en este escritor.

\section{Una Literatura de la Desnudez.}

La economía de recursos tanto lingüísticos como temáticos, es una de las características más notorias de la obra de Díaz Solís. Economía que si se manifiesta ya desde sus primeros cuentos se irá acentuando de manera progresiva hasta llegar a esos textos en los que se escamotea todo lo que no sea esencial para provocar el efecto deseado sobre el lector. Por eso los títulos que integran lo que que podría considerarse la segunda etapa de su obra "Crótalo", "El cocuyo", "Entre las sombras", "Arco secreto" y "Ophidia" entre otros- 
carecerán de manera absoluta de ciertos atributos comunes en sus primeros cuentos. Díaz Solís accede aquí a un lenguaje al que podría llamarse neutro. Ninguna marca en él indica territorialidad, extracción de clase del hablante, origen, grado de instrucción., ni nada que pueda de algún modo asociarlo con un intento de expresar ciertos contenidos de tipo social por medio de un habla particular. Otro tanto sucede con los nombres de los escasos personajes que subsistirán en sus cuentos. Personajes que, construidos con una rigurosa economía de recursos, se llamarán en lo sucesivo con apelativos igualmente que poco significan per se y en no pocas ocasiones con denominaciones genéricas al estilo de "El Joven" "El Cazador", "El Niño", etc.

Nada que exceda esa especie de tarjeta de visita parca y escuetísima del personaje necesita Díaz Solís para lanzarse a continuación al desarrollo de la historia. Ello es posible porque el entorno, tanto el natural como el social, dejan de ser relevantes. El entorno social simplemente desaparece porque no hay en el autor ninguna intención de reflejo que vaya más allá del individuo. El entorno natural y geográfico, por su lado, importa sólo en esas ocasiones en que la naturaleza es la contraparte del personaje; en tales casos ella misma funciona como actante.

De modo que no se trata ya de la naturaleza que rodea al negro Kalasán en "Llueve sobre el mar", cargada de valores y fuerzas míticas. El misterio que se desprende del entorno allí es el mismo misterio que puede percibirse en la visión asombrada de la naturaleza de los cronistas españoles. La naturaleza en un cuento como "El niño y el mar" en cambio no se percibe como ente maravilloso. Días Solís la ha desvestido en este caso de su condición de fuerza desmesurada y ha renunciado, además, a la presencia del elemento mágico tan del gusto de una cierta mirada exotizante de la literatura latinoamericana de este siglo. ${ }^{3}$ En efecto, la naturaleza, única presencia que se enfrenta a ese niño que se aventura en la bajamar a la búsqueda de cangrejos, en poco se relaciona con su antecesora omnímoda y todopoderosa. La fuerza que el mar desarrolla frente al niño "íngrimo" es una fuerza psicológica, por decirlo de alguna manera. Nada hay en el cuento que nos remita a lo mágico o a lo sobrehumano. Hay allí una tensión explosiva entre el niño que con un palito intenta atrapar al cangrejo escondido bajo una piedra y la presencia en claroscuro del animal que apenas deja adivinar su existencia pero genera al mismo tiempo un choque de voluntades que a pesar de su violencia y carga simbólica jamás abandona el campo de lo estrictamente humano. Aquí, incluso lo desconocido se perfila a escala humana. El sentimiento de ansiedad, minusvalía o ignorancia frente a lo natural nunca opta por la explicación mágica o religiosa. Cuando más se refugia en una especie de silencio poético que resalta simplemente la imposibilidad del hombre de comprenderlo todo.

En "Arco secreto", David es empleado de una empresa petrolera y habitante de un campo construido por ésta para su personal. David acrecienta a lo largo del relato una situación anímica cargada de tensión y angustia. El lector puede percibir como se tensa la cuerda de ese arco que se anuncia en el título y que no es otro que el espíritu todo del personaje que gana fuerza en una progresión perfecta que hace de este cuento uno de los mejores del autor. En la escena final el hombre se enfrenta con un animal que revolotea en

\footnotetext{
${ }^{3}$ Véase Víctor Bravo, Magias y maravillas en el continente literario (Caracas: Editorial La Casa de Bello, Colección Zona Tórrida, 1988).
} 
la penumbra de su habitación. Al igual que en "El niño y el mar" y en "Hechizo", Díaz Solís juega a cargar el elemento natural de un misterio insondable:

De pronto un blando aire gris pasa sobre el cuerpo secretamente vivo en el humo del sueño. Desaparece ligero por la puerta de la habitación. Pero en la puerta reaparece, vuelve, vuelve. Desaparece de nuevo, vuelve. Aire negro de sombra alada y loca pasa sobre el cuerpo secretamente vivo en el humo del sueño ("Arco secreto").

La escena final sin embargo no deja dudas de que la única fuerza que actúa en el relato es la que encierra ese hombre condenada a vivirse y revivirse en una especie de autofagia cuya violencia pugna por manifestarse. Y ese murciélago que revolotea ciego por la habitación termina siendo víctima de otra fuerza igualmente ciega que:

levanta el cuchillo y lo hunde otra vez, otra vez en el cuerpo de seda blanduzco. Chilla el animal y muestra sangre en los dientecillos de pez tragado por una rata. ... La punta del cuchillo se hunde otra vez, otra vez. El hombre suda, perfectamente solo. Hunde el filo, toca hueso, hace girar el mango del cuchillo en la mano dura como garra ("Arco secreto").

Los ejemplos de la naturaleza sirviendo como reflejo de la problemática anímica del hombre podrían multiplicarse a lo largo de esta etapa de la obra de Gustavo Díaz Solís. "La efigie" o "El punto" no demostrarían nada que contradijera lo afirmado hasta este momento. Pero refirámonos para concluir con este tópico a "Cachalo", especie de nueva versión de "El niño y el mar", donde de nuevo se produce un enfrentamiento con la naturaleza, personificada en este caso por un "corroncho" al que el niño vigila por semanas enteras intentando hacerlo salir de la cueva donde se esconde en el rio que corre cerca de la casa. De nuevo aquí Díaz Solís ha creado la atmósfera de suspenso acostumbrada. Dos fuerzas se oponen y el resultado no parece ser previsible. Hasta que con un arpón por él inventado el niño se metió al agua:

La punta de acero se acercaba despacio a la silueta negra del cachalo, destacaba ya sobre la recamada textura del dorso. Y súbito lo clavó. ... Entonces el muchacho como paleando levantó el cachalo atravesado por la aguja, lo sacó del agua ... Alzado así el muchacho lo vio agonizar un rato en el sol. ... Lo tomó luego por la cola y de un movimiento súbito hacia arriba lo tiró al río" ("Cachalo").

Reafirmamos que lo que caracteriza los cuentos de Días Solís es esencialmente la creación de una atmosfera que envuelve a sus personajes en tensiones y fuerzas que van más allá de las acciones, a veces inexistentes, que se narran. 


\section{Simbología de la Serpiente}

\section{Valor femenino}

Tres valores: mujer, muerte y divinidad son algunos de los que pueden identificarse con la serpiente en la obra de Gustavo Díaz Solís, quien desde sus primeros libros ha mostrado especial preferencia por la inclusión de este representante del reino animal. El primer aspecto, la femineidad de la serpiente, la atestiguan multitud de culturas a lo ancho del mundo y del tiempo y está ligada al hecho cierto de su ambigüedad, lo que le confiere un valor simultáneamente femenino y masculino. El Dictionnaire des Symboles de Seghers ${ }^{4}$ afirma que numerosos documentos iconográficos tanto en culturas asiáticas como amerindias el cuerpo fálico del animal está decorado con rombos que simbolizan la vulva femenina. Gaster, por su lado, alude a la tradición popular de los árabes palestinos entre quienes "la serpiente macho (llamada arbid, malévolo) es considerada malintencionada y destructora, mientras que a la hembra (llamada bayeh) se la tiene como benefactora y es la guardiana de los santuarios".

El tratamiento como elemento femenino de la serpiente se inicia en Díaz Solís de modo por demás evidente en "Ophidia". Este texto narra la muerte de la serpiente que le da nombre a manos de un cazador que habita con su esposa en plena selva. El relato cuenta de la venganza que el compañero de Ophidia ejecuta en la persona de la mujer del cazador.

Siguiendo las incontables experiencias de humanización de animales en la literatura universal, el autor establece un claro paralelo entre los personajes hombre-mujer, por un lado, y Ophidia-narrador, por el otro. Del mismo modo que acentúa el enfrentamiento entre los dos personajes masculinos -enfrentamiento que no es sino otro modo de identificación - se recalcan los rasgos que aproximan a Ophidia y a la mujer en la imaginación del narrador, hasta el punto de que los atributos de la serpiente muerta son los mismos que le confieren femineidad a la mujer:

La mujer logró interesarme. Debo confesar que tenía gracia. No sé si las flexiones de sus brazos me obligaron a asociar la imagen a los movimientos de Ophidia o si en su andar había algo de las voluptuosas contorsiones de mi desaparecida compañera ("Ophidia").

La asociación se establece así recurriendo no sólo al rol que cada personaje desempeña en relación a su grupo social, por decirlo de una manera, ni por determinadas peripecias que identifiquen sus desempeños como personajes del cuento; Díaz Solís recurre, antes bien, a una caracterización que destaca los atributos "propios de su sexo" en ambos casos.

Está claro que no se trata de un procedimiento original de Díaz Solís. No pocas páginas de la literatura nos hablan de identificaciones semejantes especialmente en el campo de las leyendas y de las novelas de caballería en las que se extrema el elemento fantástico.

\footnotetext{
${ }^{4}$ Seghers, Dictionnaire des Symboles, Septième édition (París 1974).

${ }^{5}$ T. H. Gaster, Mito, leyenda y costumbres en el Libro del Génesis (Barcelona: Barral Editores, 1973) 53.
} 
Howard Rollin Patch, por ejemplo, en El otro mundo en la literatura medieval, ${ }^{6}$ refiere que en el Chinon of England, de Christopher Middleton, el héroe tropieza con una cueva en la que habita una serpiente con cara de mujer. No es de extrañar en todo caso que un valor simbólico tan extendido en diversas culturas haya terminado por producir expresiones literaria o tradiciones en las que la serpiente y la muJer encarnan en un mismo cuerpo.

Lo cierto es que en "Ophidia" Díaz Solís ha llevado la identificación hasta un grado de explicitud que difícilmente pasará desapercibido al lector. No es exagerado hablar incluso de la función sexual de la serpiente, función que queda demostrada en la escena en la que el cazador utiliza el cadáver de Ophidia para sorprender a su mujer y consecuentemente poseerla en el piso de la cabaña al lado mismo de la serpiente muerta, en un acto lleno de ruidos y movimientos. La presencia de la serpiente embellece a la mujer haciéndola más atractiva a los ojos del hombre. Recurramos de nuevo a Rollin Patch quien, refiriéndose a un relato recopilado hacia 1440, describe una celebración en la cual llegada cierta hora las mujeres se encerraban en un salón especialmente elegido para tal efecto transformándose en état de couleuvres et de serpents, volviendo cada una con su compañero después de medianoche más hermosa que nunca (247).

Lo que sucede al cazador, estimulado por la presencia del cadáver de Ophidia y por la impresión que produce sobre su compañera, parece suceder igualmente en el ánimo del narrador-serpiente. Así, llegados al final del relato, cuando éste se dispone a vengar la muerte de Ophidia en la mujer compañera del asesino, su percepción del personaje está igualmente mediatizada por la identificación de aquélla con la serpiente muerta. Hasta tal punto avanza esta identificación que la venganza ejecutada se sume en una intencional ambigüedad en la que al lector le será difícil precisar si lo que se produce es la muerte por asfixia de la mujer o la absorción e incorporación al cuerpo de la serpiente a causa de un abrazo con mucho de expresión sexual.

Un proceso identificatorio semejante y su asociación con el sexo puede encontrarse en otro cuento del autor titulado "Llueve sobre el mar". El personajes principal de este cuento, el Negro Kalasán, mordido por una serpiente en un día de faena, cambiará su natural pacífico y moderado y pasará a ser un poseído del deseo hasta el punto de violar a la hija del comisario del pueblo.

De modo diferente en el cuento "La efigie" el elemento femenino está dado por la presencia predominante del agua. La historia de un cazador guiado por un indio en lo intrincado de la selva y la múltiple presencia de serpientes a lo largo del relato se resuelve en la muerte del indio a manos del cazador quien se defiende a su vez del intento de aquel de asesinarlo. La escena se desarrolla en un ojo de arenas movedizas que recuerda la materia prima, la substancia primordial de la serpiente, espiritu de todas las aguas, al decir del Seghers.

El valor femenino de las aguas ha sido bastante documentado en los tratados de simbología y en los de psicoanálisis en los que se le suele asociar con el útero materno, origen del hombre. La tradición grecolatina por su parte la considera "principio primordial y primigenio de todos los seres", según Tales de Mileto. Siguiendo esta creencia se la

\footnotetext{
${ }^{6}$ Edward Rollin Patch, El otro mundo en la literatura medieval (México: Fondo de Cultura Económico, 1983) 320.
} 
suponía madre de todos los dioses: "Como una madre puede dar a luz a un niño, así el agua puede engendrar a un dios".

Pero la serpiente es sexualmente ambigua al participar tanto del carácter femenino como del masculino. No debe extrañar entonces que en la obra de Díaz Solís, en la que campean las serpientes, podamos rastrear, además de la anotada identificación con lo femenino, su contraparte masculina. Así sucede en "La efigie", en la que llegado un momento el personajes principal, el cazador, ejecuta una maniobra destinada a salvar su vida en la que es fácil percibir el acercamiento a un tipo de conducta que asociaremos a la serpiente. Atrapado por arenas movedizas el personaje se ve obligado a reptar por sobre el cadáver del indio que momentos antes intentara asesinarlo. Poco tiempo atrás había tropezado con "una descomunal serpiente de agua, gorda y embarrada (que) se extendía a sus pies". Ahora, ante la perspectiva de la muerte, él mismo, "con violentos esfuerzos logró estirarse boca abajo sobre la masa gris. ... Tenía el barro en la boca, en las ventanas de la nariz. Era un barro hediondo que mareaba". Es evidente que el narrador juega con la identificación entre el cazador y un personaje tácito cuya presencia sin embargo será palpable para el lector a lo largo de todo el relato: la serpiente. Esta omnipresencia se explicará al final cuando el cazador descubra la dimensión divina que reviste la serpiente a los ojos de la tribu del indio muerto.

Es indispensable detenerse, por su alto valor significativo, en el escenario que Díaz Solís escoge para el desarrollo de la escena anteriormente comentada. No es gratuita la asociación con el elemento agua y su valor de lugar de origen, de asunción de una nueva esencia. Recuérdese que "la inmersión en las agua equivale no a una extinción definitiva, sino a una reintegración pasajera a lo indistinto, seguida de una nueva creación, de una nueva vida"?

Se verá que la presencia de la muerte y su asociación con el elemento serpiente no esta ausente ni por un momento de las páginas de los relatos de Díaz Solís, ni siquiera cuando es otro valor diferente al de muerte el que predomina relacionado con la serpiente. No podía ser de otra manera. La muerte en la cultura occidental, como es bien sabido, se asocia con la serpiente desde los tiempos de la feliz, aunque breve, estancia de Adán y Eva en el Paraíso. De hecho ella es origen y causa de la muerte en el pensamiento judeocristiano y como tal ha permanecido a lo largo del tiempo. Frente a la serpiente no hay más alternativa que la de sufrir la muerte o la de producírsela; por eso la Virgen María le aplasta la cabeza simbolizando el acabamiento del mal y del demonio encarnado en el reptil.

\section{Muerte}

La primera imagen de "Ophidia" es la de muerte: "Mi vida está detenida al margen de su vida apagada". La muerte es principio y fin del relato y está presente en todas las situaciones que se desenvuelven a lo largo de sus páginas aunque coexistan otros valores. En la escena del coito entre el hombre y la mujer, por ejemplo, la procreación, efecto

\footnotetext{
${ }^{7}$ Mircea Eliade, Lo sagrado y lo profano, $2^{\mathrm{a}}$ edición (Madrid: Editorial Guadarrama, 1973), 113.
} 
posible de la unión carnal, procede de la presencia palpable de la muerte por medio del cadáver de Ophidia. Origen y fin plasmados en un mismo símbolo, serpiente que se muerde la cola e imposibilitada de morir renace de sus propias cenizas. No se olvide que el cuento se estructura a partir de un paralelo entre las parejas de Ophidia y su compañero, que narra la historia de la muerte de aquélla, por un lado, y la del hombre y la mujer por el otro. La muerte, pues, refuerza la identificación entre la serpiente y la mujer o mejor aun, refuerza, el valor femenino de la serpiente. El final del cuento, como decíamos arriba, manejará igualmente la dualidad mujer-muerte invirtiendo el sentido en que ésta marcha. Si aquí lo hace desde el animal hasta el hombre, antes lo hizo en sentido inverso equiparando definitivamente las dos instancias.

"La efigie" es también prolífico en imágenes de muerte. Desde la calidad de cazador del personaje, esto es: productor de muerte; hasta la recurrencia con que ésta se presenta en los acontecimientos narrados y en el ambiente en el que ocurren. Nada hay en este relato que no connote misterio y muerte. El cazador y el indio se mueven en "un bosque muerto", confiriéndole de este modo a la naturaleza un papel cómplice con la presencia recurrente de la serpiente. En el grandioso templo de la muerte se mueven el cazador dispuesto a dar muerte, el indio que morirá en el intento de asesinar y la serpiente que pasa de la muerte a la vida en un alarde de omnipotencia que el final del relato se encargará de corroborar.

Otro tanto ocurre en "El punto": un joven cazador apostado a la espera de alguna presa descubre una pequeña víbora que pasa bajo sus piernas justo en el momento en que se dispone a disparar sobre un animal que abreva. La muerte de la serpiente evitará la muerte de la presa adquiriendo así un carácter ceremonial y de sacrificio que parece ser muy del gusto de Díaz Solís. Al igual que Cristo en el rito católico, en sus cuentos se muere para dar vida tal y como sucede con la víbora de "El punto" o con el indio que en "La efigie" muere intentando salvar de la muerte a su animal totémico.

\section{Divinidad}

El valor muerte es indesligable del misterio y de la azarosa condición de divinidad de la serpiente en diversas mitologías. En el caso concreto de nuestro cuentista es llamativo que la serpiente, al simbolizar muerte, no se asocie en general a la imagen de la serpiente como dios del mal, profundamente arraigada en la conciencia de Occidente. No se cumple pues la afirmación de Seghers, según la cual "en todos los casos ella expresa el aspecto terrestre, es decir la agresividad y la fuerza de la manifestación del gran dios de la tinieblas que es universalmente la serpiente". ${ }^{8}$ Contrariamente, en Díaz Solís, su valor parece estar asociado a una experiencia positiva de la naturaleza a la cual la serpiente se integra de modo armónico y es la presencia del hombre, bien sea desde una perspectiva depredadora, como en "Ophidia" y "El Cazador", o desde un ángulo en el cual pretende él mismo integrarse a la naturaleza, como en "El punto", quien irrumpe alterando un estado de cosas esencialmente virginal donde el mal como constituyente no existe. Señalemos como antecedente de este particular tratamiento de la serpiente, los cuentos de Horacio Quiroga,

\footnotetext{
${ }^{8}$ Seghers 183.
} 
en no pocos de los cuales la serpiente es guardián de la integridad de la selva frente a la furia destructora del hombre.

En "La efigie", la serpiente se rodea de atributos míticos e indescifrable y su relación con el "indio" es de abierta posesión. Ella habita en los adentros del hombre dictando su conducta. La condición de hecho misterioso se refuerza por medio del persistente silencio que el indio guarda frente al cazador negándose a hacerlo partícipe de sus pensamientos 0 de su percepción sagrada de la serpiente omnímoda que domina el relato. Esa presencia oculta es percibida sin embargo por el cazador quien no puede sino responder a la fuerza que emana del silencio del indio. Así, llegado un momento, "el cazador vio una serpiente que subía suavemente por un árbol. Se predispuso a dispararle, pero sintió que el indio sonreía en sus adentros y confundido, bajó el arma y se quedó mirando como hechizado la fina serpiente que ya alcanzaba las ramas altas" (44).

Esa misma proyección mágica que lo paraliza frente a la mirada del indio la percibirá de nuevo de su fuente directa en las lineas finales del cuento: "Y entonces logró ver borrosamente detrás de la humareda, la efigie de una gran serpiente que lo miraba penetrantemente con un ojo iracundo y desproporcionado desde el resplandor del fuego que asaltaba la piedra" (51). Nótese la explícita asociación de la serpiente con la concepción católica de la divinidad como gran testigo del desempeño humano. La serpiente, que ha seguido al cazador a través de la mirada del indio, se descubre ahora observándolo a través de un "ojo iracundo y desproporcionado" del cual parece imposible escapar.

El valor sagrado y mágico de la serpiente es igualmente evidente en "Llueve sobre el mar", uno de los relatos de la primera etapa del escritor. Su aparición está ligada por un lado a la figura del brujo Simangal de quien se dice tiene el don de la clarividencia, y por el otro, con el poder - maligno en este caso- de su mordida sobre el negro Kalasán. Simangal es un punto de referencia, siempre oculto, para los personajes del cuento y se le menciona como un oráculo: "Simangal dice y es verdá". Aunque Díaz Solís no lo establece de manera explícita, quedará claro que una oculta relación une a Simangal y a la serpiente hasta el punto de ocupar aquel el lugar del sacerdote en un rito misterioso cuya víctima propiciatoria será el negro Kalasán.

Tal poder se hace presente por medio del proceso de posesión del negro que se inicia con la mordida. En tanto en el plano físico Kalasán resulta ser inmune al veneno que se le inyecta, en el plano anímico se inicia con la mordida un proceso de cambio y de "locura" que lo conducirá a la muerte. El efecto mágico se refuerza en el cuento recurriendo a cánticos y expresiones que recuerdan en su cadencia los utilizados en los rituales de cultos negroides que tanto abundan en el continente. "¡Soy un negro caliente y la culebra que pica y mata no me hace ná. Simangal lo dice y es verdá!"

Que la mordida arrastre al negro Kalasán a la destrucción y la muerte extrañándolo de su propia personalidad, es un hecho que difícilmente podemos dejar de asociar con la concepción bíblica de la serpiente. Díaz Solís se acerca aquí a una visión del animal mucho más acorde con una larga tradición que se remonta mas allá de La Biblia. Testimonio de ello nos lo ofrece Theodor Gaster:

para el autor bíblico la serpiente es ciertamente siniestra así como astuta y con ello se hace eco de una tradición muy popular que cuenta con abundantes testimonios. Los árabes por ejemplo, sostienen la idea de que todas las serpientes son demonios en potencia, 
y Mahoma enseñó a sus seguidores a que mataran las serpientes tan pronto como las vieran. Los Hurones del Canadá dicen que la serpiente es la causa de todas las enfermedades, y los aborígenes de Victoria, Australia, que fue ella la que introdujo la muerte en el mundo. ${ }^{9}$

Diferente será el tratamiento dado a la serpiente y a su valor mágico en "El punto". La particularidad más notoria de este cuento es la de que el acontecimiento narrado, si puede hablarse de acontecimiento, sucede íntegramente en la psiquis del personaje. Lo que se narra es un hecho interior ligado con el escenario externo en que se desenvuelve sólo en la medida en que los elementos que constituyen ese escenario estimulan el proceso interior del sujeto.

Nos encontramos aquí con un verdadero rito de iniciación. El personaje, un joven cazador, es apostado por un baqueano en plena selva en un veladero frente a un ojo de agua donde deberá aguardar a su presa. El ritual de la iniciación no puede ser más explícito: dejado a su propio albedrío por esa especie de sacerdote que es aquí el baqueano, el muchacho debe "velar" al igual que los antiguos caballeros en un espacio cuyo valor sagrado no puede menos que sobrecogerlo.

Díaz Solís aporta, a lo largo de las breves páginas que conforman el relato, elementos suficientes para resaltar este carácter sacramental de lo acaecido. Comienza asociando la experiencia del joven cazador con el elemento árbol bajo el cual se le ha construido un parapeto. Ese mismo árbol, que, al decir de Eliade, "ha llegado a expresar todo lo que el hombre religioso considera real y sagrado por excelencia", ${ }^{10}$ se proyectará después, magnificándose, en el bosque como totalidad frente al cual el joven cazador "siente que lo toma una pasión tranquila, secreta, intensa, que ahora, como otras veces cuando está solo, mana y se revela; y siente que ahora la puede revelar, dejar libre, como era posible pensar abiertamente en Dios en la capilla del colegio que había dejado hacía cinco años y a la que nunca había vuelto" (102).

Poco margen para comentario deja la explícita asociación que el narrador hace entre el bosque y la capilla del colegio, confiriéndole así, al primero, un carácter sagrado propicio para el rito de iniciación al que se somete el personaje. Ese mismo atributo se había manejado antes para el bosque en el caso de "La efigie", relato en el que el ambiente participa de la sacralidad de la serpiente venerada por la tribu a la que pertenece el indio que sirve de guía al cazador.

Ligado al carácter sacro del elemento vegetal, en "El punto" se refuerza el tema añadiendo el elemento agua. Recuérdese que el joven está apostado en un veladero frente a un ojo de agua y que el agua reviste en sí misma de igual modo un marcado valor sacramental estrechamente relacionado con la serpiente. No en balde "innumerables mitos representan serpientes o dragones que controlan las nubes, que habitan los estanques y alimentan el mundo de las aguas fecundantes". ${ }^{11}$

Y por supuesto que no tardará en aparecer la serpiente para tomar parte en este ritual. Bajo las piernas cruzadas "en una $\mathrm{X}$ desplomada", que es un modo de decir que forman

\footnotetext{
${ }^{9}$ T. H. Gaster 52-53.

${ }^{10}$ Mircea Eliade 128.

"Gilbert Durand, Las estructuras antropológicas de lo imaginario (Madrid: Taurus, 1982) 304.
} 
una cruz, para apelar al símbolismo cristiano, el joven cazador descubre una coral venenosa. Pero no es la primera aparición del elemento serpiente en el relato. Poco antes, en el momento en que descubre a un picure que ha llegado para beber y se dispone a matarlo siente que "del cerebro le baja un estremecimiento espeso como una serpiente que se deslizara por la rama caída de un árbol" (108).

Ambas serpientes tienen como función evitar que se rompa el encanto que en ese momento integra al cazador al bosque sagrado y a una comunión consigo mismo que Díaz Solís recalca con creces. La pequeña coral es pues el animal propiciatorio cuya muerte redime al cazador. 
